\title{
A Comparison of Two Heterogeneous Catalysis Mechanisms
}

\author{
Jiamin Jin \\ Shanghai Research Institute of Materials, Shanghai, China \\ Email:jjm82@163.com
}

How to cite this paper: Jin, J.M. (2019) A Comparison of Two Heterogeneous Catalysis Mechanisms. Modern Research in Catalysis, 8, 25-37.

https://doi.org/10.4236/mrc.2019.83003

Received: July 4, 2019

Accepted: July 28, 2019

Published: July 31, 2019

Copyright () 2019 by author(s) and Scientific Research Publishing Inc. This work is licensed under the Creative Commons Attribution International License (CC BY 4.0).

http://creativecommons.org/licenses/by/4.0/

\begin{abstract}
In this paper, two heterogeneous catalysis mechanisms are introduced, namely: Chemical Reaction Mode Cyclic Catalysis Mechanism-CRMM and Electron Orbital Deformation-Recovery Cyclic Catalysis Mechanism-EODRM (or Electron Cyclic Donate-Adopt catalysis Mechanism-ECDAM. A number of difficulties encountered by CRMM are listed. The author clearly points out that CRMM is not credible. This false theory has misled us for more than 100 years. About EODRM or ECDAM, the article also gives a brief description. The key point of EODRM or ECDAM is that catalysts do not participate in chemical reactions, and catalysis phenomena are physical rather than chemical phenomena. It's completely different from CRMM. The theory contains three main points: 1 ) There is a demarcation between the catalyst and the poison; 2) The active size of the catalyst or the poison size of the poison is closely related to the electronegative size of the catalyst or poison; 3) The active size of catalyst is closely related to the chemical state. The selectivity of catalyst is related to energy level. Photocatalysis, electrocatalysis, laser catalysis and microwave catalysis are all physical phenomena. It has different energy levels. According to this theory, the author thinks that there are several problems worth studying in production and scientific research, such as: alumina in the $\mathrm{Fe}$ ammonia synthesis catalyst has a serious poison effect on the iron catalyst, resulting in three high situations in ammonia synthesis production (high temperature, high pressure, high energy consumption). The support materials of automotive exhaust purification catalyst have used Cordierite $\left(2 \mathrm{MgO}-2 \mathrm{Al}_{2} \mathrm{O}_{3}-5 \mathrm{SiO}_{2}\right)$ ceramic honeycomb support, which has a serious poisoning effect on noble metal catalysts, a lot of noble metals are wasted, and so on. These problems have long been ignored by the catalytic academia; the author considers that this reason may be due to a misunderstanding or mistranslation on the term "catalysis" and "catalyst".
\end{abstract}

\section{Keywords}

Heterogeneous Catalysis, Catalysis Mechanism, CRMM, EODRM 


\section{Introduction}

The chemical and physical properties of solid catalysts affect the catalytic activity of catalysts at the same time. The result is that the catalysis phenomena are very complicated and were regarded as mysterious and not amenable to rational interpretation. For a long time, the selection study of catalysts is always in the skill stage of the laboratory. The author thinks that the reason is lack of correct theoretical guidance.

At present, it can be seen from literature that there are two heterogeneous catalysis mechanisms. One is the widely adopted CRMM, and it is raised to the height of the "principle" by the scholars; this CRMM is also instilled in high school textbooks. It can be said that CRMM is deeply rooted in catalytic academia. Unfortunately, the CRMM has obvious errors and misleading.

Another catalysis mechanism is EODRM or ECDAM. The EODRM or ECDAM is completely different from CRMM, which holds that catalytic phenomena are physical rather than chemical phenomena, and that catalysts do not participate in chemical reactions. So far, no experimental results have been found that contradict this theory. The electrocatalytic, photocatalytic, microwave catalysis, laser catalysis are all physical phenomena, only different energy levels.

In fact, this paper is actually a summary of the author's research on the heterogeneous catalysis mechanism for more than 50 years and calls again, it is hoping that senior scholars of catalysis academia can recognize the errors of CRMM, do not go further and further on the wrong path, to avoid greater economic and resource losses.

\section{Present Situation on the CRMM}

The scholars follow the idea of "catalysis" word, how does catalyst to accelerate chemical reaction? Senior scholars of catalysis academia always adopted CRMM to illustrate. The catalysis mechanism of carbon gasification reaction in metallurgical and energy production is almost entirely illustrated by the OTM (Oxygen-Transfer Mechanism-OTM), OTM is the mechanism of oxidation-reduction cyclic reaction, it is also. CRMM In high school textbooks CRMM as a catalytic principle of biocatalyst enzyme is also adopted. It is often seen in the Internet and WeChat that academic experts always explain the catalytic mechanism of catalyst to high school students by using CRMM. In other words, the interpretation or understanding on the "catalysis" is all that the catalyst takes part in the chemical reaction, it speeds up the reaction velocity.

In the Catalyst Handbook [1], the expression for the CRMM is as follows;

$$
\begin{aligned}
& \mathrm{R}+\mathrm{M} \rightarrow \mathrm{X} \\
& \mathrm{X} \rightarrow \mathrm{P}+\mathrm{M}
\end{aligned}
$$

where $\mathrm{R}$ is reactant, $\mathrm{P}$ is product, $\mathrm{M}$ is catalyst, $\mathrm{X}$ is intermediate. The catalyst $\mathrm{M}$ takes part in a chemical reaction and regenerates the same catalyst as original after reaction. From reactant to product, $\mathrm{R} \rightarrow \mathrm{P}$, it does not generate, Instead, the 
intermediate is generated by catalyst with reactant, and then the product is generated by the intermediate. The reason is that such a reaction requires lower energy.

In the high school textbooks on the catalytic mechanism of biocatalyst enzyme, it is also based on CRMM.

Reactant + enzyme $\rightarrow$ intermediate $\rightarrow$ product + enzyme

Enzymes take part in chemical reactions, produce intermediate compounds, and finally release the same enzymes as original. The Enzymes are constantly decomposed and generated.

In 2009, Deutschmann et al. [2] had wrote a book, [Heterogeneous catalysis and solid catalysts]. In this book, two "principles" advocated by the catalysis academia are repeatedly mentioned. One is the Sabatier principle, and the other is the Boudart principle, which author call as the S-B principle.

The Sabatier principle was proposed in 1902. It's in the book: “The Sabatier principle proposes the existence of an unstable intermidiate compound formed between the catalyst surface and at least one of the reactants. The intermediate must be stable enough to be formed in sufficient quantities and labile enough to decompose to yield the final product or products". Boudart principle is the definition of catalyst given again by Boudart in 1992. It's in the book: "The most fundamental principle in catalysis is that of the catalytic cycle. A catalyst is a that transforms reactants into products, through an uninterrupted and repeated cycle of elementary steps in which the catalyst is changed through a sequence of reactive intermediate, until the last step in the cycle regenerates the catalyst in its original form.". The number of cyclic reactions per unit time is defined as the catalytic activity of the catalyst [TOF:unit:s-1]. The cycle times before the failure of the catalyst are defined as the service life of the catalyst.

The CRMM is raised to the "principle". It can be seen that their belief on the CRMM is not ordinary.

A senior American scholar studied the catalysis of the noble metal Pt on the $\mathrm{C}$ $+\mathrm{H}_{2} \mathrm{O}$ reaction, they also adopted CRMM to account for the catalysis mechanism. They believed that $\mathrm{Pt}$ is continuously reduced and oxidized by hydrogen and water in the catalysis process. That is also Oxgen Transfer MechanismOTM. Although the "proposed" mechanism is written in the paper.

Mckee D. W. [3] has studied the catalysis of the alkali metal oxides and their salts, alkaline earth metal oxides and their salts, transition group metals and their oxides, noble metals and other catalysts on $\mathrm{C}+\mathrm{O}_{2}, \mathrm{C}+\mathrm{CO}_{2}, \mathrm{C}+\mathrm{H}_{2} \mathrm{O}$ and $\mathrm{C}+\mathrm{H}_{2}, 4$ reactions with advanced instruments. He has done a lot of experimental studies, wrote more than 100 pages of lengthy articles. Finally, it considers that on balance specific oxidation-reduction cycles have been conspicuously successful in interpreting the effects of these compounds in the various types of carbon gasification reactions. But the "specific" word is nowhere to be seen. Although the author shows that the complex catalysis remains unclear and needs to be better studied afterward. 
In 2016, Chen ping, a young scientist from Dalian institute of chemical compounds, Chinese Academy of Sciences, and other researchers published a highlevel paper in the international top academic Journal (Nature Chemistry). They have proposed the design theory of "dual-activation center" ammonia synthesis catalyst. Two activation centers such as TM (transition group metal) and $\mathrm{LiH}$ are continuously decomposed and regenerated in the catalyzing process of ammonia synthesis. In fact, they also follow the "S-B principle" or the traditional ancient CRMM principle. It can be seen that the younger generation also inherited the idea of "catalysis". Of course, the use of $\mathrm{LiH}$ instead of the traditional application of alkali metal salt, reducing the synthesis temperature, it should be said to be a big breakthrough. According to EODRM, it will be so, because the electronegativity of $\mathrm{LiH}$ has to be less electronegativity than sodium carbonate.

There are many similar articles. In terms of the above several articles, from Sabatier's principle proposed in 1902, Boudart's principle on definition of catalyst in 1992 a book published by Deutschmann et al. in 2009, to the "double active center" theory proposed by Chen ping et al. in 2016 on the ammonia synthesis catalyst, the CRMM were repeatedly adopted for to account for the catalysis mechanism of catalyst.

It can be said that "CRMM" are really deep-rooted in the academia, and have entered the high school textbooks.

\section{Difficulties Encounted of the CRMM}

According to the S-B principle, the CRMM contains three contents, namely:

1) The catalyst must participate in a chemical reaction.

2) It must have intermediate compound.

3) It has to regenerate the catalyst as original form.

The most basic of the three is that the catalyst must take part in a chemical reaction and it is a cyclic reaction. But the CRMM met with great difficulty.

a) $\mathrm{BaCO}_{3}$ catalyst

The $\mathrm{BaCO}_{3}$ is commonly used as catalyst in solid carburizing agent. At the beginning, the mechanism of carbonate decomposition to release $\mathrm{CO}_{2}$ which reacts with carbon to produce carbon monoxide and thus increasing the rate of carburization was used to account for the reason for accelerating carburizing rate. Later, it was found that $\mathrm{CaCO}_{3}$, which can release a large amount of carbon dioxide, but it has no catalytic activity, while barium carbonate, which does not decompose at the carburizing temperature, has carburizing activity. Therefore, the mechanism of carbon dioxide release was abandoned and the Oxygen Transfer Mechanism, namely OTM, was adopted.

Namely:

$$
\begin{gathered}
\mathrm{BaCO}_{3}+\mathrm{C}=\mathrm{BaO}+2 \mathrm{CO} \\
\mathrm{CO}=\mathrm{CO}_{2}+[\mathrm{C}] \\
\mathrm{CO}_{2}+\mathrm{BaO}=\mathrm{BaCO}_{3}
\end{gathered}
$$


The OTM is also CRMM. This is a typical cyclic catalytic reaction. $\mathrm{BaO}$ is an intermediate compound, and the $\mathrm{BaCO}_{3}$ is constantly decomposed and generated in the carburizing process.

The equilibrium pressure of reaction (1) was measured by author [4]. At the carburizing temperature $946^{\circ} \mathrm{C}$, the value is $0.226 \mathrm{~atm}$., which is much lower than the $1 \mathrm{~atm}$. of carbon monoxide pressure in the carburizing box. It indicates that the $\mathrm{BaCO}_{3}$ cannot be decomposed by carbon, that is, the $\mathrm{BaCO}_{3}$ does not take part in chemical reaction and the cyclic reaction "decomposition-generating" cannot occur.

b) $\mathrm{Fe}, \mathrm{Co}, \mathrm{Ni}, \mathrm{Cu}, \mathrm{Ag}$ catalysts and $\mathrm{SiO}_{2}, \mathrm{~S}$ poisons

The authors have done a few times verification experiments refer to the CRMM and EODRM. These have included the active size of catalyst and poison size of poison such as $\mathrm{Fe}, \mathrm{Co}, \mathrm{Ni}, \mathrm{Cu}, \mathrm{Ag}, \mathrm{W}, \mathrm{Mo}, \mathrm{K}_{2} \mathrm{CO}_{3}$ and $\mathrm{SiO}_{2}, \mathrm{~S}$.

The experimental results show that $\mathrm{Fe}$ etc. have catalytic activity on carbon gasification reaction. The activity of iron is largest. They relative activities are $\mathrm{Fe}>\mathrm{Cu}, \mathrm{Fe}>\mathrm{Ni}, \mathrm{Cu}>\mathrm{Ni}, \mathrm{Ag}>\mathrm{Cu}$ and $\mathrm{Co}>\mathrm{Ni}$. $\mathrm{The}_{\mathrm{SiO}_{2}}$ and $\mathrm{S}$ are poison. The poison of $\mathrm{SiO}_{2}$ appears to be more poison than $\mathrm{S}$

- The experimental results agree well with EODRM, it indicates that EODRM is credible. At the same time, it also strongly proves that CRMM is not credible. Because they can't take part in a chemical reaction in the reaction box. Because there's a lot of solid carbon in the reaction box. Thermochemical data can completely prove that $\mathrm{Fe}, \mathrm{Co}, \mathrm{Ni}, \mathrm{Cu}$ and $\mathrm{Ag}$ can only take the form of metallic state. The oxidation-reduction cyclic reaction cannot absolutely occur in box.

The CRMM could not explain the relative activity of different catalysts, nor the poison of $\mathrm{SiO}_{2}$ and $\mathrm{S}$.

For same chemical reaction, such as a carbon gasification reaction, there are many catalysts, although the relative active is different. If according to CRMM, the catalyst must participate in chemical reactions, there are bound to be many chemical reactions and many intermediate compounds. For example, $\mathrm{BaCO}_{3}$ catalyst, the intermediate seen by author has barium oxide, metal barium. For the $\mathrm{Na}_{2} \mathrm{CO}_{3}$ catalyst, the intermediates seen by author are metal sodium, sodium oxide and sodium carbide, each said his own, it is dazzling. It leads the research of catalysis mechanism to bottomless abyss.

c) The CRMM can not explain why many catalysts can undergo decomposition-generation or oxidation-reduction reactions under the same reaction conditions, nor why the same catalyst can undergo cyclic reactions over a wide range of temperatures.

d) In the $\mathrm{C}+\mathrm{H}_{2}$ reaction system without oxygen, $\mathrm{Pt}$ and so on have catalytic activity, the CRMM is helpless. Because it's not possible to have oxidation-reduction cycles in this system.

e) As mentioned above, Boudart has studied the catalysis of Pt on $\mathrm{C}+\mathrm{H}_{2} \mathrm{O}$ reaction, the catalysis mechanism proposed at last is that $\mathrm{Pt}$ is continuously oxi- 
dized and reduced by water and hydrogen at low temperature $\left(400^{\circ} \mathrm{C}-500^{\circ} \mathrm{C}\right)$. That is to say, the catalysis mechanism of Pt was explained by CRMM. There is an old Chinese saying; the gold fears no fire. According to the metal oxide formation standard free energy, $\mathrm{Pt}$ is much more stable than $\mathrm{Au}, \mathrm{Pt}$ can never be oxidized by water, the oxidation-reduction cyclic reaction of $\mathrm{Pt}$ is absolutely impossible. The CRMM is also helpless.

f) To make a popular example, housewives in Shanghai know that to sprinkle some salt to a dying coal stove will make the stove prosperous, it shows that $\mathrm{NaCl}$ has catalytic activity on carbon combustion. If according to CRMM, $\mathrm{NaCl}$ should be both decomposed and generated, and they should smell the irritating and unpleasant chlorine gas, but they don't. $\mathrm{NaCl}$ is a very stable compound, it can only be broken down by electrolysis. It will never react with carbon. The CRMM is also helpless.

In order to illustrate that CRMM is not credible, the author has cited so many examples, it seems to be a bit wordy, but, when we think that the CRMM is very popular and a long time, so author also had to say a little more. More examples can be cited to explain that CRMM is not credible. In fact, more examples can be cited to explain that CRMM is not credible.

As mentioned above, it clearly tells us that the catalyst does not participate in the chemical reaction, the reversible cyclic chemical reaction is impossible to happen, it is not appropriate to raise CRMM to the "Principle". The use of "TOF" to indicate the activity of the catalyst or catalyst life is obviously out of thin air. Therefore, it is obviously inappropriate to interpret or interpret "catalysis" as "catalysis". The "catalysis" and "catalyst" have clearly misleading.

What is the cause of such a serious and simple mistake? Because of this basic knowledge of chemistry, a chemist cannot fail to understand, the author was puzzled. Therefore, the author considers that this mistake may come from the misunderstanding or mitranslating on the "catalysis" and "catalyst" words. follow the beaten track and follow the herd.

The "catalysis" word in the English, in the English-Chinese Dictionary early published, the Chinese translation of "catalysis" word is "contact reaction", "contact action", "catalysis(action)". In the later dictionary, the "cantact" word is gone, there's only "catalysis."Therefore, the author consulted Prof. Zhang Dezhong, a senior English professor from East Chtna Shanghai normal university. According to Prof. Zhang: the "catalysis" word was completely discarded. In terms of the study paper on the heterogeneous catalysis published by various foreign scholars, interpretation or understanding on the "catalysis" word is at all that the catalyst took part in the chemical reaction, thus it is to accelerate the reaction speed. There is no meaning of "contact" at all. The acknowledge on the "catalysis" and "catalyst" word by academic experts and linguists tends to agree. The "catalysis" word means that the catalyst takes part in a chemical reaction and thus speeds up the reaction.

Literally, "catalysis" and "contact" seem have completely different meanings. 
The word "catalysis" contains both take part in chemical reaction and acceleration chemical reactions, and the "contact" word, if it is a verb, this is only "contact", there is no meaning of chemical reaction or chemical change. It is obviously unreasonable to put two different meanings of Chinese together. Because "catalysis" belongs to the chemical category, and "contact" belongs to the physical category. In language academic circles on the meanings of the "catalysis" has been unified, the author considers that they are enough serious and responsible. Unfortunately, it brings serious misleading to us.

\section{EODRM or ECDAM}

Back in the 1960s, based on the experimental results and theoretical analysis, the author points out that the "principle" of CRMM is not credible [4]. Unfortunately, it didn't get attention.

The ECDAM or EODRM were proposed in the 1970s, and has been experimentally verified by author [5] [6] [7] [8]. The ECDAM or EODRM contains three main arguments. Scheme 1 is a imagine figure of catalyzing and poisoning. Adsorption of reactant leads to electron movement and electronic orbital deformation. The desorption leads also to the recovery of the electronic orbitals. The catalyzing process is the continuous deformation-recovery process of the electronic orbitals or the continuous donate-accept cyclic process of the electron. However, the orbital deformation has never reached the degree of crystal reconstruction, that is, it has not reached the degree of chemical reaction. It's just electrons moving, electron orbitals deforming.

1) From Figure 1, the coordinate " 0 " point is a demarcation between the catalyst and the poison or inhibitor. For the carbon gasification reaction, this

(a)

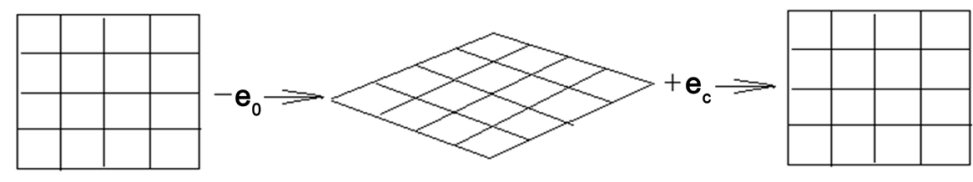

(b)

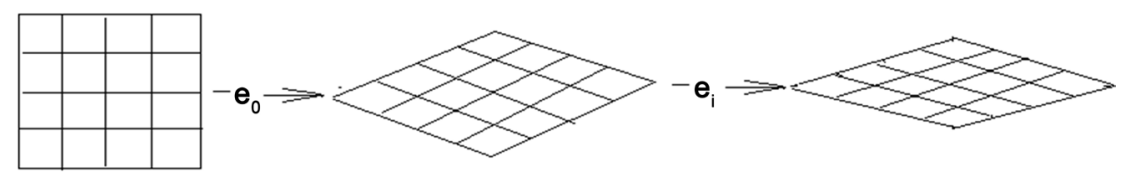

$-e_{0},-e_{i}-$ electron is seized by oxygen or inhibitor; $+e_{c}-$ electron is donated by catalyst or promoter.

Scheme 1. The imaginative catalyzing and poisoning model. (a) Catalyzing; (b) Poisoning.

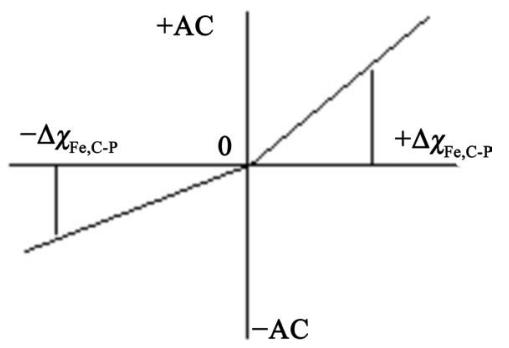

Figure 1. Relationship between electronegativity differences and catalytic activities. 
demarcation is the electronegativity of the carbon, $\chi_{\mathrm{c}}=2.55$. Any elements or compounds with electronegativities greater than 2.55 are a poison, such as $\mathrm{S}, \mathrm{Cl}$, $\mathrm{SiO}_{2}, \mathrm{Al}_{2} \mathrm{O}_{3}$. Any elements or compounds less than 2.55 is a catalyst, such as $\mathrm{Fe}$, $\mathrm{Co}, \mathrm{Ni}, \mathrm{Cu}, \mathrm{Pt}$. For iron-based ammonia synthesis catalyst, the demarcation is the electronegativity of iron, $\chi_{\mathrm{Fe}}=1.83$. Any elements or compounds with electronegativities greater than 1.83 are a poison, and any elements or compounds less than 1.83 are a catalyst. $\mathrm{C}, \mathrm{N}, \mathrm{S}, \mathrm{Cl}, \mathrm{Ni}, \mathrm{Cu}, \mathrm{Al}_{2} \mathrm{O}_{3}, \mathrm{SiO}_{2}$ etc. are all poisons. For the noble metal catalysts, the demarcation is the electronegativity of noble metal, $\chi_{\mathrm{Pt}}=2.28$. Any elements or compounds with electronegativityies greater than 2.28 is a poison, and any elements or compounds less than 2.28 are a catalyst.

2) In Figure $1, \Delta \chi_{\mathrm{Fe}, \mathrm{C}-\mathrm{P}}-$ Footnote $\mathrm{Fe}, \mathrm{C}$ are $\mathrm{Fe}$ or $\mathrm{C}, \mathrm{Pt}, \mathrm{Ni}$, etc. $\square \mathrm{P}$ represent poison, promoter or support, such as $\mathrm{S}, \mathrm{P}, \mathrm{Cl}, \mathrm{C}, \mathrm{SiO}_{2}, \mathrm{Al}_{2} \mathrm{O}_{3}$, cordierite etc.

$\Delta \chi_{\mathrm{Fe}, \mathrm{C}-\mathrm{P}}$-is difference value of electronegativities between iron or carbon and poisons.

$\Delta \chi_{\mathrm{Fe}-\mathrm{P}}=0$, this is demarcation.

Ac-express catalysis activities. The greater the positive values, the higher the catalytic activity. The greater the negative value, the greater the poison.

When $\Delta \chi_{\mathrm{Fe}, \mathrm{C}-\mathrm{P}}>0$, the $\mathrm{P}$ is catalyst. The greater the positive values of $\Delta \chi_{\mathrm{Fe}, \mathrm{C}-\mathrm{P}}$, the higher the catalytic activity.

When $\Delta \chi_{\mathrm{Fe}, \mathrm{C}-\mathrm{P}}<0$, the $\mathrm{P}$ is poison. The greater the negative values of $\Delta \chi_{\mathrm{Fe}, \mathrm{C}-\mathrm{P}}$, the higher the poison.

For example:

For the Fe catalyst in the carbon gasification, $\Delta \chi_{\mathrm{C}-\mathrm{Fe}}=\chi_{\mathrm{C}}-\chi_{\mathrm{Fe}}=2.55-1.83=$ +0.73 , it shows that the Fe is a catalyst.

For the $\mathrm{Cl}$ in the carbon gasification, $\Delta \chi_{\mathrm{C}-\mathrm{Cl}}=\chi_{\mathrm{C}}-\chi_{\mathrm{Cl}}=2.55-3.16=-0.61$, it shows that the $\mathrm{Cl}$ is a poison

For the $\mathrm{Cu}$ in the carbon gasification, $\Delta \chi_{\mathrm{C}-\mathrm{Cu}}=\chi_{\mathrm{C}}-\chi_{\mathrm{Cu}}=2.55-1.90=+0.65$, it shows that the $\mathrm{Cu}$ is a catalyst.

For the $\mathrm{Cu}$ in the iron based ammonia synthesis, $\Delta \chi_{\mathrm{Fe}-\mathrm{Cu}}=\chi_{\mathrm{Fe}}-\chi_{\mathrm{Cu}}=1.83-$ $1.90=-0.07$, it shows that the $\mathrm{Cu}$ is a poison.

For the $\mathrm{Al}_{2} \mathrm{O}_{3}$ in the iron based ammonia synthesis, $\Delta \chi_{\mathrm{Fe}-\mathrm{Al}_{2} \mathrm{O}_{3}}=\chi_{\mathrm{Fe}}-$ $\chi_{\mathrm{Al}_{2} \mathrm{O}_{3}}=1.83-2.5=-0.67$, it shows that the $\mathrm{Al}_{2} \mathrm{O}_{3}$ is a poison.

For carbon gasification reactions, the copper is catalyst. But for iron based ammonia synthesis catalysts, the copper is a poison.

3) The catalytic actives of the catalysts are closely related to the chemical states of the catalyst. The chemical states of the catalyst changed, the molecular electro-negativity changed also, therefor the catalytic active was different.

For example:

Iron has three chemical states, namely $\mathrm{Fe}, \mathrm{FeO}$ and $\mathrm{Fe}_{2} \mathrm{O}_{3}$. For carbon gasification reaction, $\mathrm{Fe}$ has catalytic active, $\mathrm{FeO}$ has no catalytic active, while $\mathrm{Fe}_{2} \mathrm{O}_{3}$ is poison at high temperature.

For carbon gasification reaction, for alkali metal carbonates, their relative catalytic active is $\mathrm{Cs}_{2} \mathrm{CO}_{3}>\mathrm{K}_{2} \mathrm{CO}_{3}>\mathrm{Na}_{2} \mathrm{CO}_{3}$. For alkaline earth metal carbonates, the their relation catalytic active is $\mathrm{BaCO}_{3}>\mathrm{SrCO}_{3}>\mathrm{CaCO}_{3}>\mathrm{MgCO}_{3}$. 
It has been verified by several experiments, In particular, the results of many experimental studies by other scholars, it is demonstrated that EODRM or ECDAM is credible. According to this theory, it is possible to judge the catalyst or the poison, to compare the actives of the catalysts or the poison of the poisons, and to select and judge the support material of catalyst.

Electronic Cyclic Donate-Accept or Electronic Orbital Deformation-Recovery Cycle is the core idea of ECDAM or EODRM. Catalysts do not participate in chemical reactions, there is no intermediate, It's just the adsorption of the reactants and the desorption of the products, adsorption and desorption will appear electronic movement, electronic movement led to orbital deformation, and the power of electronic movement is the difference of electro-negative or energy.

Therefore, the author believes that the catalytic phenomenon should be a physical phenomenon, not a chemical phenomenon. Adsorption and desorption caused by the electronic cyclic donate-accept and electronic orbital deformationrecovery cycle, are all physical phenomena. Therefore, it is more reasonable to interpret "catalysis" as "cantact". In this way, there will be no S-B principle, and there will be no many chemical reactions and bizarre intermediate compounds that are completely at odds with the fundamentals of thermodynamics.

In modern times, electrocatalysis, photocatalysis, microwave catalysis and laser catalysis seem to be physical phenomena, which coincide with EODRM.

\section{Problems Existing in the Research and Production of Heterogeneous Catalysis}

According to EODRM, it is found that there are many problems worthy of study in the field of research and production of multiphase catalysis.

\subsection{Iron-Based Ammonia Synthesis Catalyst}

This catalyst is considered by the academic community to be a classic catalyst. It is also the most studied catalyst. It has been used for more than 100 years. The chemical composition of the catalysts produced in different countries is almost the same. It's $2.5 \%-3.0 \%$ aluminum oxide. It is called structural promoter. However, according to EODRM, Alumina is poisonous to iron. Its poison is comparable to that of sulfur. The allowable content of sulfur in ferro-based catalysts is $<0.003 \%$, The content of alumina is 1000 times times that of sulfur, which seriously poisons the catalytic activity of iron. The author thinks that there are three high situations in synthetic ammonia production, which may be caused by improper use of alumina.

\subsection{Ruthenium-Based Ammonia Synthesis Catalyst}

The Ruthenium-based ammonia synthesis catalyst has been developed by British-American two companies cooperative study after for more than 10 years. The support material of the catalyst Ruthenium is the activated carbon after with high temperature graphitizing. According to EODRM, $\Delta \chi_{\mathrm{Ru}-\mathrm{C}}=2.2-2.55=$ 
-0.35 , The active carbon is poison to Ruthenium catalyst. The use of this support, must use more noble metals, the result is that the catalyst is very expensive.

\subsection{Catalyst Support for Automobile Exhaust Purification}

The most frequent type of catalytic converter in automobiles is the three-way catalyst (TWC) for stoishiometrically operated gasoline engines with an annual production of over $60 \times 10^{6}$ units [3]. The TWC systems contain Pt, Pd and Rh. The catalytic components are supported by a cordierite honeycomb monolith coated with high surface area $\gamma-\mathrm{Al}_{2} \mathrm{O}_{3}$. According to EODRM, the cordierite $\left(2 \mathrm{MgO}-2 \mathrm{Al}_{2} \mathrm{O}_{3}-5 \mathrm{SiO}_{2}\right)$ is acid material, it is poison to noble metal catalyst, In order to meet emission standards, more catalysts must be used.

In order to meet higher emission standards, The Germans have developed the Fe-Cr-Al metal coil honeycomb support. Compared with cordierite ceramic honeycomb carriers, at the same emission standard, noble metals loaded with metal coil honeycomb support are approximately $1 / 2$ of the ceramic support. This clear indication that inappropriate support materials can waste a lot of noble metals catalyst.

The second support, i.e. $\gamma-\mathrm{Al}_{2} \mathrm{O}_{3}$ plating layer is also poison to noble metal catalyst. Fortunately, rare earth oxides are gradually replacing alumina.

The automobile catalyst is developing in a reasonable direction, which is in perfect agreement with EODRM's expectation.

\subsection{Diesel Exhaust Soot Filter}

Diesel exhaust soot filter, at present, it is still the cordierite ceramic honeycomb wall flow filter used. The cordierite is a poison to carbon, filters made of this material, regeneration is too slowly, it cannot be used continuously. As a result, Americans use dual filters, one job and the other to regenerate, with the result that prices are too expensive to promote. From the internet, It is recommended by a domestic factory, when the filter is blocked, the back pressure goes up a certain value, the filter is removed, then with high-pressure gas reverse blowing, so that its regeneration. Thus it can be seen this problem that has plagued people for years is still unresolved as yet. The term "advanced cordierite" was used by entrepreneurs to promote their products and was clearly misleading. Cordierite is used as honeycomb carrier material because of its small expansion, and it is not easy to be broken during repeated heating and cooling. However, it is toxic to carbon gasification and precious metal catalyst in terms of chemical properties.

\subsection{Fuel Cell etc.}

From the internet, the support of fuel cell Platinum catalyst is made by carbon black or graphite at early stage. Later, the carbon nanotube is developed. The catalyst support of denitrification in power plant adopts cordierite ceramic honeycomb or stainless steel mesh. Alumina and active carbon are mass produced as noble metal catalyst support in many factories around the world. High strength, 
high melting point, high specific surface area, high chemical stability, abundant resources and so on are the advantages of alumina, active carbon. However, they are poison to metal catalysts, noble metal catalysts, unreasonable carriers, will consume more precious metals. The use of unreasonable support materials will consume more expensive noble metals.

There are so many problems in scientific research and production. The author considers that the main cause is the lack of correct theoretical guidance and it interpreted the "catalysis" as "accelerated chemical reaction" and the catalyst has to participate in the chemical reaction.

\section{Discussion}

\subsection{Misleading Effect on the "Catalysis" and CRMM}

To compare the CRMM and EODRM, the CRMM is beset with difficulties, however, the EODRM was a wide expanse of flat land, so far no contradiction has been met, so the EODRM is credible.

According to the EODRM, the heterogeneous catalysis is a physical rather than a chemical phenomenon, the catalysts do not participate in chemical reaction, the relationship between the catalyst and the reactants or products is only adsorption or desorption. The unbounded suspended electrons on the catalyst surface are the factor that lead to adsorption; the electronegative difference is the power that leads to electron movement, adsorption and desorption are the causes of electron donate-accept and orbital deformation-recoversion. Neither the adsorption of the reactant and nor the desorption of the products involve chemical reactions, but only electron movement and orbital deformation, and no intermediate compounds are produced. Electrocatalysis, photocatalysis, microwave catalysis, laser catalysis and so on are all physical phenomena, and they have different energy levels.

According to the S-B principle, the definition by Boudart on the "catalyst" and unified understanding or interpreting on the "catalysis" and "catalyst" by Catalytic academic and linguists, The author considers that "catalysis", "catalyst" and "TOF" have a misleading effect.

Because the "catalysis" has a misleading effect, it is better to change "catalysis" to "contact" "contactor". As for the term "contact", "contactor", is it appropriate, it is need to ask linguists to verify.

The other is still using "catalysis" and "catalyst", because scholars have used it for a long time.

But the understanding or interpreting on the "Catalysis" and "catalyst" for scholars must change, that is, the "catalyst" does not participate in the chemical reaction. This "TOF" dimension can never appear in the literature again.

\subsection{Unitization on the Catalysis Mechanism}

- There are many heterogeneous catalytic reactions, thereof now it is using EODRM or ECDAM as a unified catalytic mechanism, it seems extremely 
worrying. Fortunately, the good news is that over 40 years of observation on catalytic reactions of carbon gasification, catalytic reactions of iron based ammonia synthesis, and noble metal catalysis, no contradiction or serious contradiction has been found so far. Author firmly believes that the ECDAM or EODRM is reliable. It should be a basic theory of heterogeneous catalysis.

- The application of electrocatalysis, photocatalysis, microcatalysis, lasercatalysis and the reasonable development of automobile catalyst are a powerful proof. Because these developments are completely consistent with ECDAM or EODAM's mechanism.

\subsection{Electronegativity and Selectivity}

The electronegativity was used to determine the activity or poison of the material, the relative activity and the selection of support material, some might think it's too simplification, the selectivity of the catalyst is no more involved. However, if we associate electronegativity with energy levels, and then we associate energy levels with selectivity, then it's not so simple. Highly selectivity of biocatalyst enzymes may be related to their molecular electronegativity and energy levels. It's like video. Electrocatalysis, photocatalysis, microwave catalysis and laser catalysis have different energy levels, and they can catalyze different products, which may be a powerful testament.

Maybe the highly selective of biocatalysts are related to electronegativity and energy levels of biocatalyst, and new highly active catalyst can be easily developed. But the author knows nothing about these.

The author's knowledge is poor, improper, please kindly correct it.

\section{Conflicts of Interest}

The author declares no conflicts of interest regarding the publication of this paper.

\section{References}

[1] (1982) Catalyst Handbook. Beijing Chemical Industry Press, Beijing, 464.

[2] Deutschmann, O., Knozinger, H., Kochloefl, K. and Turex, T. (2009) Heteroegeneous Catalysis and Solid Catalysts. Wiley-VCH Verlag GmhH \& Co. KGaA, Weinheim.

[3] Mckee, D.W. (1981) The Catalyzed Gasification Reactions (Chemistry and Physics of Carbon). Marcel Dekker, New York.

[4] Jin, J.M. (1966) Carburizing Effect of Carbonate in Solid Carburizer. Proceedings of the First National Annual Conference on Heat Treatment, Chinese Society of Mechanical Engineering, Beijing Machine Press, Beijing, 389.

[5] Jin, J.M., Jia, G.Y., Reng, J.Y. and Zhu, Z.Z. (1982) Mechanism of Catalysis and Poison of Mineral Impurities in Carbon on Carbon Reduced Ferric Oxide. National Conference on Metallic Powders.

[6] Jin, J.M. and Bao, W.F. (2012) Re-Exploring the Relationship between Noble Metals Catalyt and Suppor Materials. Materils Review, 26, 52. 
[7] Jin, J.M. and Bao, W.F. (2018) Study on the Mechanism of Heterogeneous Catalysis. (2) The Relative Catalytic Activities of $\mathrm{Fe}, \mathrm{Co}, \mathrm{Ni}, \mathrm{Cu}, \mathrm{Ag}$ and $\mathrm{SiO}_{2}$ in the Carbon Catalyzed Gasification Reaction. Journal of Materials Science and Chemical Engineering, 6, 191-201. https://doi.org/10.4236/msce.2018.64018

[8] Jin, J.M. and Bao, W.F. (2018) Study on the Mechanism of Heterogeneous Catalysis (4)-Electron Cyclic Donate-Accept Catalysis Mechanism-ECDAM or Electron Orbital Deformation-Reversion Cyclic Catalysis Mechanism-EODRM. Journal of Materials Science and Chemical Engineering, 6, 15-30.

https://doi.org/10.4236/msce.2018.68003 